\title{
Fitness profiling in women soccer: performance characteristics of elite Turkish women soccer players
}

\author{
İbrahim $C A N^{1}$, Aras Beka YASAR ${ }^{1}$, Serdar BAYRAKDAROGLU ${ }^{1}$, Beyza YILDIZ1 \\ Gumushane University, School of Physical Education and Sport, Gumushane, TURKEY \\ Address Correspondence to I. Can, e-mail: ibrahimcan@gumushane.edu.tr
}

\begin{abstract}
The aim of this investigation was to evaluate an overall performance of the elite women football players. In accordance with this purpose, 11 women football players (age: $21,5 \pm 2,58$ years; height: $160,8 \pm 5,17 \mathrm{~cm}$; weight: 55,8 $\pm 7,23 \mathrm{~kg}$ ) who plays in Turkish Women's $1^{\text {st }}$ Football League participated voluntarily. In order to measure athlete's aerobic capacity, Yo-Yo intermittent recovery test (Yo-Yo IR1) was applied and maximal oxygen uptake $\left(\mathrm{VO}_{2 \max }\right)$ values were estimated by using running distances obtained from the test results. The Wingate anaerobic power test (WanT) to measure the athlete's anaerobic properties, the vertical jump (VJ) and standing long jump (SLJ) tests to determine explosive power, the Illinois agility test to measure agility skills, 10 and 30 meters sprint runs to measure sprint performances, hand grip and back-leg strength tests to measure strength characteristics were used. In order to obtain power and velocity parameters, loaded-squat jump (SJLoaded) was applied with an resistance that equaled to $40 \%$ of body weight and bench throw (BT) was applied with an resistance that equaled to $30 \%$ of body weight of the participants by applying an isoinertial device and results of peak power (PP), peak velocity (PV), mean propulsive power (MPP), and mean propulsive velocity (MPV) during both movements were recorded. Statistical analysis was used in the assessment of the data. According to analysis results, it was achieved that Yo-Yo IR1 running distances was as $676,3 \pm 156,4$ meters, while $\mathrm{VO}_{2 \max }$ values of athletes were estimated as $42,2 \pm 1,20 \mathrm{ml} / \mathrm{kg}^{-1} / \mathrm{min}^{-1}$. Relative and absolute anaerobic power values for elite women football players were obtained as 439,7 $( \pm 61,18 \mathrm{~W})$ and 8,04 $( \pm 1,09 \mathrm{~W} / \mathrm{kg})$ for maximal anaerobic power, 316,1 $( \pm 34,46 \mathrm{~W})$ and 5,78 $( \pm 0,56 \mathrm{~W} / \mathrm{kg})$ for maximal anaerobic capacity, 193,6 $( \pm 22,30 \mathrm{~W})$ and 3,55 ( \pm $0,61 \mathrm{~W} / \mathrm{kg}$ ) for minimal anaerobic power, respectively. In addition, fatigue index values measured as $55,7( \pm 3,75 \%)$. Participant's right and left hand grip strength values were obtained as $30,6( \pm 4,62 \mathrm{~kg})$ and 29,6 $( \pm 4,5 \mathrm{~kg})$, back and leg strength values measured as 90,2 ( $\pm 18,7 \mathrm{~kg})$ and 101,8 $( \pm 29,5 \mathrm{~kg})$, respectively. Participant's 10 and 30 meters sprint duration were obtained as $1,85( \pm 0,12 \mathrm{sec})$ and $4,96( \pm 0,34 \mathrm{sec})$. SLJ, VJ and agility values were obtained as $178,4( \pm 21,1 \mathrm{~cm}), 35,7( \pm 4,60 \mathrm{~cm})$ and 17,6 ( $\pm 0,67 \mathrm{sec})$, respectively. Velocity and power values for athletes during BT movement were obtained as 1,21 $( \pm 0,10$ $\mathrm{m} / \mathrm{sec})$ for MPV, $2,04( \pm 0,18 \mathrm{~m} / \mathrm{sec})$ for PV, 353,6 $( \pm 83,2 \mathrm{~W})$ for MPP and 666,3 $( \pm 152,1 \mathrm{~W})$ for PP. In response to this, velocity and power values for athletes during SJLoaded movement were obtained as 1,21 (, $\pm 10 \mathrm{~m} / \mathrm{sec})$ for MPV, 2,04 $( \pm, 18 \mathrm{~m} / \mathrm{sec})$ for PV, $353,6( \pm 83,2 \mathrm{~W})$ for MPP and $666,3( \pm 152,1 \mathrm{~W})$ for PP. As a result, although there are many studies on physical or physiological characteristics of elite male footballers, the literature on the overall performance characteristics of women football players are limited. It is thought that the results obtained are important to fill this lack in the literature and will be the reference source for future research.
\end{abstract}

Key Words: Football, Fitness, Performance, Women

\section{INTRODUCTION}

In a football match, $80-90 \%$ of the performance is reported to be spent with moderate and low intensity walking and running while the remaining part is spent with high intensity activities $(7,15,79$, 82). Various acceleration and decelerations, frequent change of activity, directional change, unusual movement patterns and application of various technical abilities make a significant contribution to energy expenditure (79). Today, about 20 million women play football and this number equals to almost $10 \%$ of the sum of women and male football players all over the world. It is stated that the number of registered women football players increased by more than $50 \%$ in 2006 (young and senior level). The number of recreactional and professional leagues and international events for women footballers in different age categories has grown substantially in late years. This allows a wide range of women football players to practise and contend in professional environment. There is also an increased need for specific studies that can assist improving the women football players' performance expectations and performance levels (61). 
It has argued that a very good anaerobic capacity and a well-enhanced aerobic fitness are prerequisites for succeeded performance in women's football (65).In a study, it was shown that elite women footballers do an mean of 1459 (13361529) activities at a varying intensity of changing every 4 seconds per match and the number of running at high intensity is 125 (72-159) on average with a time changing per 2-3 seconds (51). In studies conducted by different authors and using different measurement techniques, it was found that women football players had a distance of $8.5-10.3 \mathrm{~km}$ in a football match $(1,2,28,33,40,65)$.

Due to the duration of a football game, aerobic capacity is extremely important for footballers (93). One of the most fundamental component determining success in an aerobic endurance sport is maximal oxygen uptake $\left(\mathrm{VO}_{2 \max }\right)$ (39). $\mathrm{VO}_{2 \max }$, expressed as the highest amount of oxygen the organism can use during one minute of exhausting exercise (43), indicates the individual's cardiovascular fitness (13). That is, it reflects the capacity of the oxygen delivery system for muscle work and shows the oxygen used by the muscles during exercise (41). $\mathrm{VO}_{2 \max }$ values of women football players were obtained to be $42-57$ $\mathrm{ml} \cdot \mathrm{kg}^{-1} \cdot \mathrm{min}^{-1}(25,28,30,33,38,47,51,57,64,65,71$, $75,81,88,90,95,97,98)$. A player having a high $\mathrm{VO}_{2 \max }$ value has the high energy storage required for energy release and a better recovery rate (43).

Most of the movements in one match are executed without the ball and mostly cover the aerobic exercises while intense anaerobic exercises are made during the movements that bring the game to its conclusion (80). According to the volume of the match, the athletes have to make sprint throws, get into the ball-fighting struggle, changing directions fast, jogging and shuttle runs. In those cases where the density increases, anaerobic metabolism is effective while aerobic metabolism is active in cases where concentration is regular and under the submaximal level (93). Anaerobic performance is the ability of the individual to maximally performing anaerobic exercise. The ability to produce the highest mechanical power (anaerobic power - peak power) in a few seconds and to sustain high power efficiency (anaerobic capacity - mean power) in short time is considered to be the main indicators of anaerobic performance (46). Anaerobic power and capacity is often used according to the consumption of two different anaerobic energy systems (48).
Today's football matches are played faster and at higher intensity. Capacity to perform different high intensity activities is important in match performance (53). Although high intensity movements contribute to the distance covered only for $\sim 11 \%$, they constitute the most important movements of the match and scoring a goal or possession of the ball make a direct contribution (80). Sprint is a high-intensity activity which takes place about each 90 seconds, every ending at an average of 2-4 seconds in a football match. This corresponds to $0.5-3.0 \%$ of the efficient playing duration, i.e. the duration of playing with the ball. It has also been found that virtually all of sprints ( $\% 96)$ in the games are shorter than 30 meters and a large generality is shorter than 10 meters $(6,78)$.

Jumping performance assesses the leg strength and is closely associated with sprint performance $(74,102)$. It is fundamental to arrive maximal speed at the moment of sprint and maximal speed depends on explosive strength (19). Explosive power and sprint rapidness are two interrelated physiological traits at high-intensity that contribute to football performance $(66,83,93)$. Explosive power is essential for the skills that are very important in the football such as jumping, sprinting and turning $(9,77,93,101)$.

Most of the football moves require fast turns. In other words, it denotes the player's fast turns in the opposite direction or to the ball. These fast turns are often called agility (103). Agility composed of the combination of equilibrium, speed, condition and strength is described as the skill to change direction in a fast and accurate way at the moment of a movement series $(34,73,99)$.

Kinetic and kinematics associated with resistance workout are thought to be an fundamental stimulant in the formation of neuromuscular adaptations (27). The maximal strength, described as the maximal strength produced by a muscle or muscle groups in the neuromuscular system at the moment of maximal contraction without any time constraint, is expressed as a repetitive maximal or $100 \%$ of maximal and denotes the heaviest weight that the athlete can lift at one time (16). Although the terms of strength and power are sometimes used interchangeably, this is not the right approach. Because power, which is one of the fundamental elements of sporting performance, has a time component and is the mechanical amount described as the temporary ratio of the work done 
(power= work/time), and it usually depends on the ability to create the highest possible strength (maximal strength) $(67,94)$. It is important to calculate the power for three different reasons. These are as follows; (1) to designate the optimal loading for resistance workout, (2) to evaluate the influence of strength workout and (3) to predict the exercise performance (49).

It is very important to apply the strength in a very short time in the athletic performance. Thus, it is necessary to display the highest possible strength in a very short time in many movements taking place in less than a second (84). The velocity, which is a vector amount, is expressed as the time-related ratio of change in the any position (104). The concentric contraction velocity of a muscle is inversely proportional to the external force or the load applied. When the executed strength is zero, the contraction rate of the muscle is the greatest. When the strength raises to a level equal to the maximal strength which strains the muscle, the rate of contraction becomes zero (12). In other words, the strength that the muscle produces increases but the speed of movement decreases as the weight increases.

There are many studies on the physiological and physical features of elite male footballers and the desires for games in the Turkish population. However, despite the increasing professionalization and popularity of women football worldwide, the studies on women's football are limited and we predict that this study will be valuable for the sports science literature. Therefore, the aim of this research is to make a general evaluation on the athletic performance characteristics of elite women football player.

\section{METHODOLOGY}

\section{Participants}

In this study, 11 women footballers (age: $21.5 \pm$ 2.58 years; height: $160.8 \pm 5.17 \mathrm{~cm}$; weight: $55.8 \pm 7.23$ $\mathrm{kg}$ ) from Turkish Women's $1^{\text {st }}$ football league voluntarily participated. The health condition of the participants is good and they don't use any drugs that may negatively affect the variables analysed. At the beginning of the study, players signed an approval document stating that they voluntarily attend in the investigation.

\section{Procedures}

\section{Height and Weight Measurement}

The height and weight measurements of players were obtained by using a Seca 769 (Seca Corporation, Hamburg, Germany) electronic measuring instrument with an accuracy of the 0.001 meter and $0.01 \mathrm{~kg}$ respectively.

\section{Yo-Yo Intermittent Recovery (Level 1) Test}

Athletes' running distances were obtained by using the Yo-Yo intermittent recovery level 1 (Yo-Yo IR1) test designed by Bangsbo (8) to determine the aerobic features of the athletes competing in team or individual sports. In this test, the athletes were made a 2x20 meter shuttle run at a gradually increasing speed within the running area determined by the cones. Each running area has another cone which is put 5 meters behind the starting point and demonstrates the recovery region. At the end of each 40-meter run, the athletes were told that they had 10 seconds to recover and they had to walk slowly or jog in the recovery zone. Afterwards, the athletes were told to stand on the starting point and wait for the signal for the next run. Running speeds were determined with audible signal sounds coming from a CD. The test was terminated when a subject was exhausted or when $\mathrm{s} /$ he failed to reach the finish line twice (10).

\section{Maximal Oxygen Uptake}

The maximal oxygen uptake $\left(\mathrm{VO}_{2 \max }\right)$ values of the participants were estimated by using the following formula according to the Yo-Yo AT1 test result.

$\mathrm{VO}_{2 \max }\left(\mathrm{ml} \cdot \mathrm{kg}^{-1} \cdot \mathrm{min}^{-1}\right)=$ IR1 running distance (m) $\mathrm{X} 0.0084+36.4(10)$.

\section{Maximal Heart Rate}

The maximal heart rate $\left(H R_{\max }\right)$ values of the athletes in the IR1 test were obtained by using the heart rate monitor (Polar M400, Finlandiya) when the test was completed.

\section{Vertical Jump Test}

After a general 10-minute warm up, athletes were subjected to a vertical jump (VJ) test. First, standard arm lengths were determined in front of the test platform and then they were asked to jump as high as possible. At the end of the test, the distance between the jump distances and standard arm lengths of the subjects was calculated and the jump distances were recorded in centimetres (56). The VJ test was performed twice by allowing adequate resting time and the best score was recorded for analysis. 


\section{Standing Long Jump Test}

After a 10-minute warm-up, the athletes performed a standing long jump (SLJ) test to determine their explosive leg strength. In this test, participants were asked to open their feet at shoulder width and to jump forward by bending their knees as their toes were behind the specified line. The distance between the toes of the participants at starting line and the place of heels where they landed was calculated and recorded in centimetres (56). The SLJ was performed twice by allowing adequate resting time and the best test value was recorded for analysis.

\section{Sprint Performance}

After a 10 minute warm-up, the athletes performed 10 and $30 \mathrm{~m}$ sprint run three times in the a static position (after $0 \mathrm{~m}$ back of the first photocell) with a 3-minute recovery period between each test period. Sprint times were determined by using an electronic photocell (Newtest Powertimer System, Newtest Oy, Oulu, Finlandiya)

\section{Agility Test}

The Illinois agility test designed by Getchell (32) was utilized to determine athletes' acceleration, directional change and agility characteristics. In this test, the 10 meter-long and 5 meter-wide test area was marked with 4 cones (start, finish and two turning points). There are 4 more cones in the middle of the test area, each with a 3.3 meter gap between them. An electronic photocell (Newtest Powertimer System, Newtest Oy, Oulu, Finlandiya) was placed at the start and finish points. The test consists of $40 \mathrm{~m}$ straight run and $20 \mathrm{~m}$ slalom (zigzag) runs between cones with $180^{\circ}$ turns every 10 meters. When the participants felt ready, the test was initiated while the participants were in a supine position and the hands were in contact with the ground at the shoulder-length and it was tried to be finished as soon as possible. Before the test started, the participants were allowed to make trials in order to be used to test area. To obtain the best performance, the test was applied twice with a 3-4 minute recovery period between each repetition and the best test time was recorded in seconds (56).

\section{Hand Grip Strength Measurement}

Athletes' hand grip strength values were obtained from both the right hand and the left hand by using a digital strain gauge dynamometer (Takei TKK5401 Takei Scientific Instruments, Tokyo).
During the measurements, the participants were allowed to extend their elbows provided that they did not touch their arms or bodies to the dynamometer. According to the standard arm position proposed by the American Society of Hand Therapists (ASHT) for the hand grip test, it is especially necessary for the participants to get their shoulders closer and rotate them independently, with their elbows bent $90^{\circ}$ and sitting with their forearms and wrists in a neutral position (31). It was stated that the subjects had to be in a standing position, grasp the dynamometer with their dominant hand and apply maximal pressure gradually for at least two seconds until the grade was recorded. After recording the result, nondominant hand was measured. The movable part of the dynamometer handle was adjusted in a way to reach the first phalange of ring finger. Athletes were permitted two trials with both hands and the best results for both hands were recorded with an accuracy of $0.1 \mathrm{~kg}$.

\section{Back and Leg Strength Measurement}

Back and leg strength values of the athletes were obtained by using back and leg dynamometer (Takei TKK5402 Takei Scientific Instruments, Tokyo).The legs were twisted in the leg strength measurement and the knees in a tensioned position in the back strength measurement. After the participants placed their legs on the dynamometer with their knees bent in leg strength measurement and the knees stretched in back strength measurement, they pulled up the dynamometer bar vertically with their arms stretched, their backs straight and their bodies leaning forward slightly (41). For each movement, the measurements were repeated twice and the best results were recorded with an accuracy of $0.1 \mathrm{~kg}$.

\section{Anaerobik Performans}

The Wingate Anaerobic Power Test (WanT) was utilized to obtain the anaerobic capacity and power values of participants. First, the subjects were informed with regard to test procedure in detail and then the test was conducted by using a computer ergometer (Monark 839E Sweden) with a compatible software and connected to a computer modified for leg. WanT is the most popular cycle ergometer test used to achieve anaerobic performance $(23,44)$ where the subject pedals against a resistance designated by the subject's body mass as fast as possible $(5,17)$. Developed at the Wingate Institute Research and Sports Department 
in Israel (96), this test is considered to be a laboratory test (11) that provides information on both lactacid (anaerobic capacity) and alactacid (anaerobic power) composition of anaerobic performance $(14,70)$. Before the test, a 5-minute warm-up protocol was applied to the participants to help hem familiarize with the test protocol. At the beginning of the test, the subject pedalled for a few seconds without a load to reach the pedal speed established. When the subject reached the predetermined pedal speed without load, a load corresponding to $7.5 \%$ of the body weight of each subject was applied as resistance and the subject tried to pedal at high speed for 30 seconds against this resistance created by this load. Pedal counts were recorded for every 5 seconds and all power parameters were calculated absolute and relative values with a computer software $(11,23,24,45,46$, 76 , 96). The parameters obtained during the Wingate anaerobic power test are given below (72).

Peak Power (Maximal Anaerobic Power): It is the highest mechanical strength achieved during any 5 -second time period during the test.

Mean Power (Maximal Anaerobic Capacity): It is the average strength produced during the test.

Minimal Power: It is the lowest mechanical strength achieved during any 5-second time period during the test.

Fatigue Index: It is the percentage expression of power reduction during the test. It is found by dividing the difference between the highest power value and the lowest value obtained in any 5 second time period during the test by the highest power obtained.

\section{Bench Throw and Loaded-Squat Jump Movements}

The bench throw (BT) movement was applied to the participants on a Smith machine (Esjim IT7001, Eskisehir, Turkey). The reason for BT movement is applied by using a smith machine instead of free weights is that this machine can provide accurate and reliable measurements by limiting the movement in the vertical direction (49). Before BT movement, the participants were applied a 20-min warm-up protocol comprised of $15 \mathrm{~min}$ of general (5 min of upper and lower-body stretching following a moderate running) and $5 \mathrm{~min}$ of particular exercises (bench press and bench throw trials at sub-maximal degree). After warm-up, subjects were stated to apply BT movement 3 times at maximal velocities with an resistance equaled to
$30 \%$ of their weight. It was stated that participants had to lower the barbell in a restrained form until they touched the chest slightly during the BT movement and then throw it as fast and as high as possible together with the start command (54).

Before loaded-squat jump (JSLoaded) movement, the subjects were applied a 20-min warm-up protocol comprised of $15 \mathrm{~min}$ of general (10 min of running following $5 \mathrm{~min}$ of upper and lower-body stretching) and $5 \mathrm{~min}$ of particular exercises (squat attempts at sub-maximal degree). After the warmup, participants were subjected to a JSLoaded test with an resistance that equaled to $40 \%$ of their weights by using free weights. During this trial, participants were requested to bring their knees to the flexion from the static position until their thighs were parallel to the ground and after the start command, they had to jump as fast as possible without allowing their shoulders to lose touch with the barbell and repeat this movement 3 times (55). If these requirements were not met, the motion was repeated. Because, addictively the external load during the JSLoaded test, the body weight must be moved and the speed and power parameters must be determined via the ability of the participants to accelerate total mass (body mass and external load) (26).

A linear converter (T-Force Dynamic Measurement System; Ergotech Consulting S.L., Murcia, Spain) was connected to the last part of the barbell in order to obtain the power (MPP: mean propulsive power; PV: peak power) and velocity (MPV: mean propulsive velocity; PV: peak velocity) parameters during the bench throw and loadedsquat jump movements. The use of this system is especially proper for any weights lifting workouts or any resistance training exercise in which it is necessary to overcome a load (a constant mass) moving along the vertical axis against gravity. The system includes an electromechanical equipment (interface and velocity sensor), a special computer program (T-force system software) that manages this equipment and a hook connected to the barbell. The velocity sensor is usually placed on the ground and measures the speed of the loads lifted by measuring how quickly the 2-meter cable is pulled and dropped through a tachogenerator with a high sensitivity within the aluminium body. In other words, the sensor provides the current proportional to the movement of the cable and allows the velocity to be directly determined in the loads where the movement is made. The cable is made of 
nylon-coated stainless steel and has a diameter of $0.50 \mathrm{~mm}$. The tension of wire $(5 \mathrm{~N})$ can withstand large accelerations, so using this system for sudden sports activities such as jumping, pulling and lifting will not be a problem. Computer transmission interface includes an electronic data acquisition board equipped with 14-bit resolution. It is connected to the computer via a USB port which allows very fast and reliable data transfer. The sampling frequency of the data obtained is fixed at $1000 \mathrm{~Hz}$. This means that instantaneous speed data in each Ms is obtained. A specifically designed hook is used to connect the power converter cable to the weight training barbell $(85,86)$.

\section{Statistical Analysis}

SPSS version 16.0 (SPSS Inc, Chicago, IL) was used for all data analyses. Descriptive statistics analysis method was used in data assessment.

\section{RESULTS}

Descriptive statistical results for some performance parameters of participants are indicated in table 1, the statistical results for the power and velocity values in SJLoaded and BT exercises are shown in table 2 and the statistical results for absolute and relative anaerobic power values are indicated in table 3.

\begin{tabular}{|c|c|c|c|c|}
\hline Variables & $\mathrm{n}$ & Minimal & Maximal & Mean (sd) \\
\hline Right hand grip strength $(\mathrm{kg})$ & 11 & 24.9 & 41.6 & $30.6( \pm 4.62)$ \\
\hline Left hand grip strength $(\mathrm{kg})$ & 11 & 23.5 & 39.3 & $29.6( \pm 4.50)$ \\
\hline Leg strength $(\mathrm{kg})$ & 11 & 62.5 & 151.0 & $101.8( \pm 29.5)$ \\
\hline Back strength $(\mathrm{kg})$ & 11 & 66.1 & 124.5 & $90.2( \pm 18.7)$ \\
\hline Standing long jump $(\mathrm{cm})$ & 11 & 130 & 210 & $178.4( \pm 21.1)$ \\
\hline Vertical jump $(\mathrm{cm})$ & 11 & 30 & 44 & $35.7( \pm 4.60)$ \\
\hline Agility (sec) & 11 & 16.73 & 19.01 & $17.6( \pm .67)$ \\
\hline 10 meters sprint (sec) & 11 & 1.70 & 2.07 & $1.85( \pm .12)$ \\
\hline 30 meters sprint (sec) & 11 & 4.57 & 5.56 & $4.96( \pm .34)$ \\
\hline Yo-Yo IR1 test $(\mathrm{m})$ & 11 & 480 & 960 & $676.3( \pm 156.4)$ \\
\hline $\mathrm{HR}_{\max }\left(\right.$ beat $\left./ \mathrm{sec}^{-1}\right)$ & 11 & 185 & 194 & $187.9( \pm 2.50)$ \\
\hline $\mathrm{VO}_{2 \max }\left(\mathrm{ml} / \mathrm{kg}^{-1} / \mathrm{sec}^{-1}\right)$ & 11 & 40.7 & 44.4 & $42.2( \pm 1.20)$ \\
\hline
\end{tabular}

Table 2. Results of the some kinetic and kinematic parameters during loaded-squat jump and bench throw movements of the elite women football players

\begin{tabular}{|c|c|c|c|c|c|c|c|c|}
\hline \multirow[t]{2}{*}{ Variables } & \multicolumn{4}{|c|}{ Bench Throw } & \multicolumn{4}{|c|}{ Loaded-Squat Jump } \\
\hline & $\mathrm{n}$ & Minimal & Maximal & Mean (sd) & $\mathrm{n}$ & Minimal & Maximal & Mean (sd) \\
\hline Load (kg) & 11 & 13.5 & 20 & $16.7( \pm 2.31)$ & 11 & 17 & 25 & $21.8( \pm 2.56)$ \\
\hline Displacement $(\mathrm{cm})$ & 11 & 57.9 & 89.6 & $77.2( \pm 9.81)$ & 11 & 44.4 & 76.4 & $62.5( \pm 8.61)$ \\
\hline $\operatorname{MPV}\left(\mathrm{m} / \mathrm{sec}^{-1}\right)$ & 11 & 0.74 & 0.95 & $.85( \pm .07)$ & 11 & 1.03 & 1.35 & $1.21( \pm .10)$ \\
\hline $\mathrm{PV}\left(\mathrm{m} / \mathrm{sec}^{-1}\right)$ & 11 & 1.32 & 1.66 & $1.44( \pm .10)$ & 11 & 1.81 & 2.32 & $2.04( \pm .18)$ \\
\hline $\mathrm{MPP}(\mathrm{W})$ & 11 & 102.7 & 181 & $140.1( \pm 26.8)$ & 11 & 237.7 & 467.1 & $353.6( \pm 83.2)$ \\
\hline $\mathrm{PP}(\mathrm{W})$ & 11 & 196.7 & 325.8 & $273.6( \pm 43.6)$ & 11 & 472.8 & 882.3 & $666.3( \pm 152.1)$ \\
\hline
\end{tabular}

MPV: Mean Propulsive Velocity; PV: Peak Velocity; MPP: Mean Propulsive Power; PP: Peak Power

Table 3. Results of the elite women football players according to absolut and relative anaerobic power values

\begin{tabular}{lllll}
\hline Variables & $\mathrm{n}$ & Minimal & Maximal & Mean $( \pm \mathrm{sd})$ \\
\hline MAP $(\mathrm{W})$ & 11 & 317.2 & 512.0 & $439.7( \pm 61.1)$ \\
\hline MAP $(\mathrm{W} / \mathrm{kg})$ & 11 & 5.97 & 9.41 & $8.04( \pm 1.09)$ \\
\hline MAC $(\mathrm{W})$ & 11 & 251.3 & 357.0 & $316.1( \pm 34.4)$ \\
\hline MAC $(\mathrm{W} / \mathrm{kg})$ & 11 & 4.46 & 6.38 & $5.78( \pm .56)$ \\
\hline $\operatorname{MinP}(\mathrm{W})$ & 11 & 147.8 & 227.2 & $193.6( \pm 22.3)$ \\
\hline $\operatorname{MinP}(\mathrm{W} / \mathrm{kg})$ & 11 & 2.48 & 4.04 & $3.55( \pm .48)$ \\
\hline FI $(\%)$ & 11 & 50.8 & 59.8 & $55.7( \pm 3.75)$ \\
\hline
\end{tabular}

MAP: Maximal Anaerobic Power; MAC: Maximal Anaerobic Capacity; MinP: Minimal Anaerobic Power; FI: Fatigue Index 


\section{DISCUSSION}

Athletic performance in football depends on many factors such as aerobic-anaerobic capacity, agility, speed, muscle power and strength $(9,93)$. A high degree of physical fitness provides the physiological basis for the players to compete with the physical requirements of matches and allows them to perform their tactical and technical skills effectually particularly towards end of the game in which fatigue starts to be felt (8). The evaluation of the physical capacities of players may indicate the demonstration of physical requirements at a certain period of the game. Since athletes must be able to adapt to the game's requirements to be succeed at the levels of competition. It is also stated that the physical requirements of the football occur more apparent as the levels of struggle increases (80).

There are many ways to determine the physiological features of athletes and the physical requirements of the match being done. Most of the field and laboratory tests such as shuttle run tests on the field or treadmill tests to determine $\mathrm{VO}_{2 \max }$ values have been designed to determine physical performance (50). Although the values obtained on the treadmill test are considered to be the "gold standard" for measuring aerobic power, there is a need for training staff, expensive equipment and a long time $(4,22,36)$. So, simple and inexpensive field tests applied to a large group of subjects were designed as alternative tests (92). Yo-Yo IR tests are one of the recently used tests. The IR1 test is a nice indicator of the ability of elite women footballers to run at high intensities during the competition-based games and can also be utilized as a demonstration of physically game effort (51).

Looking at the studies conducted on the Yo-Yo AT1 performance of women football players, it is stated that according to Sezgin et al., (88) the average running distance of the elite Turkish women football players is $676 \mathrm{~m}$ and the running distance of elite and lower-level women football players of Hong Kong is $673.3 \mathrm{~m}$ and $630.0 \mathrm{~m}$ respectively as stated by Man (57). These finding are similar to those reported in the current research. In this study, the average IR1 running distance of elite women football players has been found to be 676.3 ( \pm 156,4 $\mathrm{m})$. As different from the finding of this research, Milanovic et al., (63) have reported that the test results for women athletes from the Serbian national team playing in different positions range from 880 to $930 \mathrm{~m}$. Mujika et al., (66) have stated that average running distances of young (17.3 \pm 1.6 years) and older ( $23.1 \pm 2.9$ years) elite women football players are $826( \pm 160 \mathrm{~m})$ and $1224( \pm 255 \mathrm{~m})$, respectively. In the study conducted, the running distances of the elderly football players in the IR1 test are $48 \%$ higher than the young elite women. Krustrup et al., (51) have stated that average running distance of women football players competing in the $1^{\text {st }}$ League of Denmark is $1379 \mathrm{~m}$ on the IR1 test. In addition, while the IR1 distance of NCAA women football players has been found to be $1097( \pm 100 \mathrm{~m})(90)$; the test distance of women footballers in American üniversities have been obtained as $1120( \pm 297 \mathrm{~m})$ (58). Martinez-Lagunas et al., (59) have established that Yo-Yo IR1 running distance of German women football players at different levels is $1102( \pm 316 \mathrm{~m})$ for the women football players in the $2^{\text {nd }}$ league and $886( \pm 399 \mathrm{~m})$ for women players in the $4^{\text {th }}$ league. The findings obtained in the current research show parallelism with the findings obtained in the studies of Sezgin et al., (88) and Man (57); however, they are significantly lower than the results obtained in other studies. It can be argued that this difference is due to the fact that elite Turkish women football players have a worse condition level.

There are many researches in literature conducted to determine maximal oxygen uptake $\left(\mathrm{VO}_{2 \max }\right)$ values of women football players indirectly by using field tests and directly by using laboratory tests. In previous studies, VO2max values of Turkish women football players were obtained to be 42.08 $\mathrm{ml} \cdot \mathrm{kg}^{-1} \cdot \mathrm{min}^{-1}(88)$ and $43.1 \mathrm{ml} \cdot \mathrm{kg}^{-1} \cdot \mathrm{min}^{-1}$ (95). VO2 $\max$ values are $43.3 \mathrm{ml} \cdot \mathrm{kg}^{-1} \cdot \mathrm{min}^{-1}$ for Hong Konger women footballers (57), $57.6 \mathrm{ml} \cdot \mathrm{kg}^{-1} \cdot \mathrm{min}^{-1}$ for Danish elite women football players (47), 49,4 ml. $\mathrm{kg}^{-1} \cdot \mathrm{min}^{-1}$ (51) and $52.3 \mathrm{ml} \cdot \mathrm{kg}^{-1} \cdot \mathrm{min}^{-1}$ (52) for women football players in the $1^{\text {st }}$ league of Denmark, 49,8 $\mathrm{ml} \cdot \mathrm{kg}^{-1} \cdot \mathrm{min}^{-1}$ for women football players in the $1^{\text {st }}$ league of Italy (30), $51.4 \mathrm{ml} \cdot \mathrm{kg}^{-1} \cdot \mathrm{min}^{-1}$ for Australian national women football team (33), 53.5 $\mathrm{ml} \cdot \mathrm{kg}^{-1} \cdot \mathrm{min}^{-1}$ for Serbian elite women football players (71), $53.9 \mathrm{ml} \cdot \mathrm{kg}^{-1} \cdot \mathrm{min}^{-1}$ for NCAA $1^{\text {st }}$ league women football players (90), $54.0 \mathrm{ml} \cdot \mathrm{kg}^{-1} \cdot \mathrm{min}^{-1}$ for elite Norwegian women football players (38), 45.1 $\mathrm{ml} . \mathrm{kg}^{-1} \cdot \mathrm{min}^{-1}$ for Spanish $1^{\text {st }}$ league women football players (3), $53.9 \mathrm{ml} \cdot \mathrm{kg}^{-1} \cdot \mathrm{min}^{-1}$ for women footballers in Czech Republic premier league (18), 47.9 $\mathrm{ml} \cdot \mathrm{kg}^{-1} \cdot \mathrm{min}^{-1}$ for Australian international women football players (25), $48.4 \mathrm{ml} \cdot \mathrm{kg}^{-1} \cdot \mathrm{min}^{-1}$ for British international women football players (28), 54.8 $\mathrm{ml} \cdot \mathrm{kg}^{-1} \cdot \mathrm{min}^{-1}$ (40) and $48.5 \mathrm{ml} \cdot \mathrm{kg}^{-1} \cdot \mathrm{min}^{-1}$ (98) for Australian women players of national football team 
and $51.4 \mathrm{ml} \cdot \mathrm{kg}^{-1} \cdot \mathrm{min}^{-1}$ for Australian $1^{\text {st }}$ league women football players (33). Todd et al., (97) have found that average $\mathrm{VO}_{2 \max }$ values of British professional, international and regional women football players are $45.0 \mathrm{ml} \cdot \mathrm{kg}^{-1} \cdot \mathrm{min}^{-1}, \quad 46.8$ $\mathrm{ml} . \mathrm{kg}^{-1} \cdot \mathrm{min}^{-1}$ and $43.9 \mathrm{ml} \cdot \mathrm{kg}^{-1} \cdot \mathrm{min}^{-1}$ respectively. Martinez-Lagunas and Hartmann (60) have obtained the estimated $\mathrm{VO}_{2 \max }$ values of the elite German women football players as $49.9\left( \pm 4.9 \mathrm{ml} \cdot \mathrm{kg}^{-1} \cdot \mathrm{min}^{-1}\right)$ in IR1 test. In the present study, the estimated average $\mathrm{VO}_{2 m a x}$ values of women footballers in the elite level according to the IR1 test results were found as $42.2 \mathrm{ml} \cdot \mathrm{kg}^{-1} \cdot \mathrm{min}^{-1}$. Compared with the finding obtained for the elite women football players in the literature, it is seen that the results of our study are lower. This difference is due to the fact that elite Turkish women football players have lower aerobic capacity. Actually, when looking at the IR1 distances in the current research, elite Turkish women football players seem to cover a lower distance. Given that the $\mathrm{VO}_{2 \max }$ values are also obtained from the Yo-Yo AT1 running distance inferentially, it is an expected result to obtain a low average $\mathrm{VO}_{2 \max }$ value.

Since the amount and volume of blood in women is low, the heart needs to work faster to send the oxygen needed to the required tissues. This makes the heart to be tired quickly. Therefore, it is stated that women have low heart rate volume and high heart rate counts (87). In this study, average HRmax values of elite Turkish women football players has been found to be 187.9 beats/ $\mathrm{min}^{-1}$. Ostojic (71) found the HR $\mathrm{Hax}_{\operatorname{mal}}$ values of Serbian women football players as 183.1 beats/min-1 and average $\mathrm{HR}_{\max }$ values of Danish elite women players in the match were found to be 186 beats/ $\mathrm{min}^{-1}$ by Krustrup et al., (51). Sezgin et al., (88) and Sjökvist et al., (90) have found the HRmax values of women footballers in IR1 test as 184 and 194.9 beats/ $\mathrm{min}^{-1}$ respectively. The maximal heart rate counts were determined as 184 beats/min ${ }^{-1}$ for Spanish $1^{\text {st }}$ League women football players (3), 193 beats/ $\mathrm{min}^{-1}$ for Czech Republic Premier League women football players (18), 202 beats $/ \mathrm{min}^{-1}$ for Australian international women football players (25). In this study, it is seen that the $H_{\text {max }}$ values of elite Turkish women football players are lower than $\mathrm{HR}_{\max }$ numbers reported in other researches conducted on elite women footballers. Considering the Yo-Yo IR1 distances of the subjects, it can be argued that this difference is due to the fact that subjects did not push themselves too hard and they finished running test without allowing $\mathrm{HR}_{\max }$ values rise further. Since motivation and willingness are important factors for realistic performance of the participants in field tests. Furthermore, the test is terminated when the athlete fail in order to arrive the finish point twice in the specified duration in the Yo-Yo IR1 test according to test rules. For this reason, even if the subjects have enough energy to continue running, they may complete the running test without reaching the maximal heart rate when the test is terminated as per the rules, which may result in lower running distances and heart rate counts.

Explosive power is essential for very important abilities (e.g. jumping, sprinting, turning) in football $(9,77,83,93,101)$.In this study, the VJ and SLJ tests were applied to identify the explosive power features of the women footballers and the jump distances were obtained as $35.7 \mathrm{~cm}$ for the vertical jump test and $178.4 \mathrm{~cm}$ for the standing long jump test. Looking at literature, average vertical jump height is $35.6 \mathrm{~cm} \mathrm{(42)} \mathrm{and} 40.5 \mathrm{~cm}$ (98) for Australian women footballers, $35.3 \mathrm{~cm}$ for elite Turkish football players (95), $35.4 \mathrm{~cm}$ for women football players in Turkish $1^{\text {st }}$ League (21), $37.8 \mathrm{~cm}$ for Danish elite women players (47), $35.0 \mathrm{~cm}$ for women football players of Danish 1 ${ }^{\text {st }}$ League (52), $39.3 \mathrm{~cm}$ for British elite women football players (75), $47.6 \mathrm{~cm}$ for Serbian elite women football players (71), $30.7 \mathrm{~cm}$ for football players of Norwegian national team and $28.1 \mathrm{~cm}$ for the $1^{\text {st }}$ League women football players (37). Smith et al., (91) reported an average vertical jump height of $42.8 \mathrm{~cm}$ and $38.3 \mathrm{~cm}$ respectively for the $1^{\text {st }}$ and $3^{\text {rd }}$ league college women football players. Todd et al., (97) reported that vertical jump height for the British professional, international and regional women football players were as 49.0, 47.8 $\mathrm{cm}$ and $46.6 \mathrm{~cm}$, respectively. Göral ve Göral (35) obtained the vertical jump height of Turkish women footballers as $31.3( \pm 2.61 \mathrm{~cm})$.

Sprint is a very important characteristic of achievement in football and short sprint tests as 10 and 30 meters are widely used for determining sprint ability (42). In this study, times in the sprint tests applied to determine the sprint performances of elite Turkish women football players have been found as $1.85( \pm .12 \mathrm{sec})$ for 10 meters and $4.96( \pm .34$ sec) for 30 meters. McCurdy et al. (62) have obtained that the 10 and 25 meters test scores of women football players are 2.31 and $4.52 \mathrm{sec}$, respectively. In studies conducted on Australian women footballers, Hoare \& Warr (42) obtained 5, 10 and 20 meters sprint times as $1.23 \mathrm{sec}, 2.08 \mathrm{sec}$ and $3.63 \mathrm{sec}$, 
respectively while Tumilty \& Darby (98) achieved 20 meters sprint times of players as $3.31 \mathrm{sec}$. In addition, according to Todd et al., (97) have stated that the 5 and 30 meters sprint times of British professional, regional and international women football players are $1.04 \mathrm{sec} \& 4.64 \mathrm{sec}, 1.07 \mathrm{sec} \&$ $4.70 \mathrm{sec}$ and $1.02 \mathrm{sec} \& 4.62 \mathrm{sec}$., respectively. Krustrup et al., (52) have found 30 meters sprint running values of Denmark $1^{\text {st }}$ league women football players as $4.86 \mathrm{sec}$ while Haugen et al, (37) have found $4.35 \mathrm{sec}$ for the players of Norwegian national women football team and $4.43 \mathrm{sec}$ for the $1^{\text {st }}$ league women football players and $4.58 \mathrm{sec}$ for the $2^{\text {nd }}$ league women football players. In a study conducted by Göral and Göral (35) on Turkish women football players, the sprint speed of 30 meters was obtained as $5.67 \mathrm{sec}$.

The agility, which is expressed as a quick change of direction, is stated to be affected from balance, flexibility, muscular coordination and explosive power (89). In addition, agility is a physiological precondition in football due to the fact that players often make sudden changes of direction to be efficient in the match $(66,80)$. In this study, agility values of elite Turkish women football players have been found to be 17.6 ( $\pm .67 \mathrm{sec})$. Concerning the literature, it is observed that various tests have been used for measuring the agility skills of women football players. Vescovi and McGuigan (100) have reported that the pro-agility and modified Illinois agility test values of college women football players are $4.88 \mathrm{sec}$ and $10.24 \mathrm{sec}$., respectively. Hoare and Warr (42) have used the 505 agility test to assess the agility characteristic of Australian women footballers and achieved a mean value of $2.75 \mathrm{sec}$.

Wingate anaerobic power test (WanT) usually measures peak power (PP), mean power (MP) and fatigue index (FI) values. $\mathrm{PP}$ is the highest mechanical power achieved throughout any 5second time period in the test and the power in this duration predominantly reflects the ATP-PC (alactic) system. MP is the average power obtained throughout 30 second test period and predominantly reflects the anaerobic glycolysis energy system in the muscle. FI is the percentage expression of the reduction in power produced at the time of testing which shows the total capacity of emergency and short-time energy systems and ATP generating systems. In other words, it is obtained by dividing the PP value the difference between the minimal power and PP attained in any 5-second time period during the test $(11,20,23,24,76)$.

In this study, the absolute and relative anaerobic power values of elite Turkish women football players have been found to be $439.7( \pm 61.18$ $\mathrm{W})$ and $8.04( \pm 1.09 \mathrm{~W} / \mathrm{kg})$ respectively for maximal anaerobic power, $316.1( \pm 34.4 \mathrm{~W})$ and $5.78( \pm .56$ $\mathrm{W} / \mathrm{kg})$ for maximal anaerobic capacity, $193.6( \pm 22.3$ $\mathrm{W})$ and $3.55( \pm .61 \mathrm{~W} / \mathrm{kg})$ respectively for minimal anaerobic power and fatigue index values have been found as $55.7( \pm 3.75 \%)$. There is a limited information on the anaerobic power values of women footballers in the literature. In a study comparing the anaerobic values of Greek $1^{\text {st }}$ league women football players according to game positions, the absolute and relative power values in terms of peak power parameter are $570( \pm 63 \mathrm{~W})$ and $9.50( \pm .79 \mathrm{~W} / \mathrm{kg})$ respectively for defensive players, $658( \pm 29 \mathrm{~W})$ and $9.41( \pm .24 \mathrm{~W} / \mathrm{kg})$ for goalkeepers, $571( \pm 85 \mathrm{~W})$ and $9.44( \pm .70 \mathrm{~W} / \mathrm{kg})$ for forwards, 578 $( \pm 78 \mathrm{~W})$ and $9.57( \pm .78 \mathrm{~W} / \mathrm{kg})$ for midfielders while these values are $423( \pm 48 \mathrm{~W})$ and $7.07( \pm .83 \mathrm{~W} / \mathrm{kg})$ for defensive players, $489( \pm 14 \mathrm{~W})$ and $7.00( \pm .06 \mathrm{~W} / \mathrm{kg})$ for goalkeepers, $426( \pm 59 \mathrm{~W})$ and $7.07( \pm .87 \mathrm{~W} / \mathrm{kg})$ for forwards and $432( \pm 50 \mathrm{~W})$ and $7.21( \pm .70 \mathrm{~W} / \mathrm{kg})$ for midfielders in terms of mean power values. Fatigue index values have been obtained as $47.8( \pm 10.2 \%)$ for defensive players, $47.5( \pm 6.4 \%)$ for goalkeepers, 44.1 ( $\pm 4.9 \%)$ for forwards and $44.2( \pm 7.1 \%)$ for midfield players (68). These findings are different from the findings of our study. Tamer et al., (95) obtained the anaerobic power values of elite Turkish women football players as $96.13 \mathrm{kgm} / \mathrm{s}^{-1}$ by using the vertical jump test and the Lewis Nomogram, indicating that this value is moderate relative to the elite women football players in different countries.

In this study, the right and left hand grip values of elite Turkish women football players have been obtained as $30.6( \pm 4.62 \mathrm{~kg})$ and $29.6( \pm 4.50 \mathrm{~kg})$ respectively while back and leg strength values are $90,2( \pm 18,7 \mathrm{~kg})$ and $101,8( \pm 29,5 \mathrm{~kg})$. Nikolaidis (68) reported that the righy and left hand grip strength values of the Greek $1^{\text {st }}$ league women football players were $31.7( \pm 4.6 \mathrm{~kg})$ and $29.2( \pm 3.5 \mathrm{~kg})$ for defensive players, $33.9( \pm 8.6 \mathrm{~kg})$ and $33.0( \pm 4.4 \mathrm{~kg})$ for goalkeepers, $30.5( \pm 4.3 \mathrm{~kg})$ and $26.9( \pm 3.6 \mathrm{~kg})$ for forwards, $30.5( \pm 4.6 \mathrm{~kg})$ and $29.4( \pm 4.6 \mathrm{~kg})$ for midfield players respectively. In another study by Nikolaidis (69), the right and left hand grip strength values of women football players were obtained as $31.2( \pm 4.5 \mathrm{~kg})$ and $29.3( \pm 4.2 \mathrm{~kg})$ respectively. According to Dey et al., (29) the left and right hand 
grip strength values of the players in the women national football team of India were obtained as 31.1 $( \pm 2.78 \mathrm{~kg})$ and $29.6( \pm 3.59 \mathrm{~kg})$ respectively. The findings of this research and the findings obtained in the researches of Nikolaidis $(68,69)$ and Dey et al., (29) are similar. Unlike the results of our study, in the study by Göral and Göral (35) completed on Turkish women football players, the right and left hand grip strength values of the athletes were found to be $25.2( \pm 1.96 \mathrm{~kg})$ and $24.6( \pm 1.83 \mathrm{~kg})$ respectively while the back and leg values were $77.9( \pm 4.78 \mathrm{~kg})$ and $90.7( \pm 2.36 \mathrm{~kg})$. The results obtained in the relevant study are observed to be quite low. This difference is thought to arise from the differences in the struggle level (elite - amateur level) of women football players.

Velocity and power parameters of elite Turkish women football players during BT (\% 30 of body weight) and SJLoaded ( $\% 40$ of body weight) movements applied by using external loads were analysed with an isoinertial velocity transducer and the velocity and power values of women football players during bench throw movement were 0.85 $( \pm .07 \mathrm{~m} / \mathrm{sec})$ for MPV, $1.44( \pm .10 \mathrm{~m} / \mathrm{sec})$ for PV, 140.1 $( \pm 26.8 \mathrm{~W})$ for MPP and $273.6( \pm 43.6 \mathrm{~W})$ for PP while the velocity and power values in the SJ Loaded movement were $1.21( \pm .10 \mathrm{~m} / \mathrm{sec})$ for MPV, $2.04( \pm .18$ $\mathrm{m} / \mathrm{sec})$ for PV, $353.6( \pm 83.2 \mathrm{~W})$ for MPP and 666.3 $( \pm 152.1 \mathrm{~W})$ for PP. This is the first study in which velocity and power values of women athletes are obtained by using an isoinertial velocity transducer.

\section{CONCLUSION}

In conclusion, there are many studies on the physiological and physical features of elite level male footballers in the Turkish population and the desire for games. However, the studies conducted on elite Turkish women football players are limited despite the increasing professionalization and popularity of women football worldwide and the current study is thought to be an important source of reference for the literature of sports sciences. This study is the most comprehensive study performed on the performance qualities of Turkish women footballers at the elite level. When the finding attained from this research are compared with the finding of the researches on elite women football players performed in other countries, it is observed that the elite Turkish women football players have lower performance values and their conditions are in a worse level. Thus, it is necessary for the elite Turkish women footballers to improve their conditional characteristics, which are considered as prerequisites for successful athletic performance in order to increase their competing level and to reach a level for international competition.

\section{ACKNOWLEDGEMENTS}

This study is presented as oral presentation in the "International sport Sciences Tourism \& Recreation Student Congress" which was hosted by the Manisa Celal Bayar University, 07 to $09^{\text {th }}$ May 2018.

\section{REFERENCES}

1. Andersson H., Ekblom B., Krustrup P. Elite football on artificial turf versus natural grass: Movement patterns, technical standards, and player impressions. Journal of Sports Sciences, 2008; 26(2): 113-122.

2. Andersson HA., Randers M.B., Heiner-Møller A., Krustrup P., Mohr M. Elite female soccer players perform more highintensity running when playing in international games compared with domestic league games. Journal of Strength and Conditioning Research, 2010; 24(4): 912-919.

3. Arecheta CP., Lopez MG., Mulas AL. La importancia del $\mathrm{VO}_{2 m a x}$ para realizar esfuerzos intermitentes de alta intensidad en el futbol femenino de elite. Kronos, 2006; 5(9): $4-12$.

4. Aziz RA., Tan CK., The CK. A pilot study comparing two field tests with the treadmill run test in soccer players. Journal of Sports Science and Medicine, 2005; 4(2): 105-112.

5. Baker UC., Heath EM., Smith DR., Oden GL. Development of wingate anaerobic test norms for highly-trained women. Journal of Exercise Physiology, 2011; 14(2): 68-79.

6. Bangsbo J., Nørregaard L., Thorsøe F. Activity profile of competition soccer. Canadian Journal of Sport Science, 1991; 16(2): 110-116.

7. Bangsbo J. Energy demands in competitive soccer. Journal of Sports Science and Medicine, 1994; 12: 5-12.

8. Bangsbo J. The physiology of soccer with special reference to intense intermittent exercise. Acta Physiologica Scandinavica, 1994; 619: 1-155.

9. Bangsbo J., Mohr M., Poulsen A., Perez-Gomez J., Krustrup P. Training and testing the elite athlete. Journal of Exercise Science and Fitness, 2006; 4(1): 1-14.

10. Bangsbo J., Laia FM., Krustrup P. The Yo-Yo intermittent recovery test: A useful tool for evaluation of physical performance in intermittent sport. Sports Medicine, 2008; 38(1): 37-51.

11. Barfield PJ., Sells PD., Rowe DA., Hannigan-Downs K. Pratice effect of the wingate anaerobic test. Journal of Strength and Conditioning Research, 2002; 16(3): 472-473.

12. Bartlett R. Introduction to sports biomechanics: Analysing human movement patterns. Oxon: Routledge, 2007; 223-292.

13. Bassett RD., Howley TE. Limiting factors for maximum oxygen uptake and determinants of endurance performance. Medicine Science in Sports Exercise, 2000; 32(1): 70-80.

14. Beneke R., Pollmann C., Bleif I., Leithauser RM., Hütler M. How anaerobic is the wingate anaerobic test for humans. European Journal of Applied Physiology, 2002; 87(4-5): 388392. 
15. Bloomfield J., Polman R., O'Donogue P. Physical demands of different positions in FA Premier League soccer. Journal of Sports Science and Medicine, 2007; 6(1): 63-70.

16. Bompa OT, Di Pasquale M., Cornacchia L. Serious strength training. United States: Human Kinetics, 2012; 259-270.

17. Bradley LA., Ball ET. The wingate test: Effect of load on the power outputs of female athletes and nonathletes. Journal of Applied Sport Science Research, 1992; 6(4): 193-199.

18. Bunc V., Psotta R. Functional characteristics of elite Czech female soccer players. Journal of Sports Science, 2004; 22(6): 528

19. Bushnell T., Hunter I. Differences in technique between sprinters and distance runners at equal and maximal speeds. Sports Biomechanics, 2007; 6(3): 261-268.

20. Camille T., Plowman SA., Looney MA. Reliability and validity of the anaerobic speed test and the field anaerobic shuttle test for measuring anaerobic work capacity in soccer players. Measurement in Physical Education and Exercise Science, 2002; 6(3): 187-205.

21. Can F., Yilmaz I, Erden Z. Morphological characteristics and performance variables of women soccer players. Journal of Strength and Conditioning Research, 2004; 18(3): 480-485.

22. Castagna C. Impellizzeri MF., Chamari K., Carlomango D., Rampinini E. Aerobik fitness and Yo-Yo continuous and intermittent test performances in soccer players: A correlation study. The Journal of Strength and Conditioning Research, 2006; 20(2): 320-325.

23. Chia M. Assessing young people's exercise using anaerobic performance tests. European Journal of Physical Education, 2000; 5(2): 231-258.

24. Chia M., Armstrong N. Maximal intensity exercise (Ed: Armstrong N), Pediatric exercise physiology. China, Churchill Livingstone Elsevier. 2007.

25. Colquhoun D., Chad KE. Physiological characteristics of Australian female soccer players after a competitive season. Australian Journal of Science and Medicine in Sport, 1986; 18(3): 9-12

26. Cormie P., McCaulley GO., Triplett NT., McBride JM Optimal loading for maximal power output during lowerbody resistance exercises. Medicine Science and Sports Exercise, 2007; 39(2), 340-349.

27. Crewther B., Cronin J., Koegh J. Possible stimuli for strength and power adaptation: Acute mechanical responses. Sports Medicine, 2006; 36(1): 65-78.

28. Davies JA, Brewer J. Applied physiology of female soccer players. Sports Medicine, 1993; 16(3): 180-189.

29. Dey SK., Jana S., Bandyopadhyay A. Effect of training on various anthropometric and physiological profiles of Indian national women soccer players. European Journal of Sport and Exercise Science, 2015; 4(1): 1-9.

30. Evangelista M., Pandolfi O., Fanton F., Faina MA. Functional model of female soccer players: Analysis of functional characteristics. Journal of Sports Science, 1992; 10: 165.

31. Fess E., Moran C. Clinical assessment recommendations. Indianapolis: American Society of Hand Therapists, 1981; 124.

32. Getchell B. Physical fitness: A way of life", (2nd edition), New York: John Wiley and Sons, Inc. 1979.

33. Gabbett TJ., Mulvey MJ. Time-motion analysis of smallsided training games and competition in elite women soccer players. Journal of Strenght and Conditioning Research, 2008; 22(2): 543-552.

34. Gambetta V. How to develop sport specific speed. Sports Coach, 1996; 19(3): 22-24.
35. Göral K., Göral Ş. Examination of the relationship between sprint speed, vertical jump and strength parameters of female soccer players. MANAS Journal of Social Studies, 2015; 4(3): 116-123.

36. Grant S., Corbett K., Amjadt MA., Wilson J., Aitchisont T. A Comparison of methods of predicting maximal oxygen uptake. British Journal of Sport Medicine, 1995; 29(3): 147152.

37. Haugen TA., Tonnessen E., Seiler S. Speed and countermovement-jump characteristics of elite female soccer players. International Journal of Sports Physiology Performances, 2012; 7(4): 340-349.

38. Helgerud J., Hoff J., Wisløff U. Gender differences in strength and endurance of elite soccer players. Science and Football IV (Ed. Spinks, W., Reilly, T., Murphy A.) London Routledge: 2002; 382-402.

39. Helgerud J., Hoydal K., Wang E., Karlsen T., Berg P., Bjeerkass M. Simonsen T., Helgesen C., Hjorth N., Bach R., Hoff J. Aerobic high-intensity interval improve $\mathrm{VO}_{2 \max }$ more than moderate training. Medicine Science in Sports and Exercise, 2007; 39(4): 665-671.

40. Hewitt A., Whiters R., Lyons K. Match analyses of Australian international female soccer players using an athletic tracking device. (ed. Reilly, T., Korkusuz, F.). Proceedings of the $6^{\text {th }}$ world congress on science and football. Antalya, Turkey: Routledge, 2009; 224-228.

41. Heyward VH. Advanced fitness assessment and exercise prescription. Champaign IL: Human Kinetics, 2006.

42. Hoare DG., Warr CR. Talent identification and women's soccer: An Australian experience. Journal of Sports Science, 2000; 18(9): 751-758.

43. Hoff J. Training and testing physical capasities for elite football player. Journal of Sport Sciences, 2005; 23(6): 573582.

44. Hoffman JR., Kang J. Evaluation of a new anaerobic testing system. Journal of Strength and Conditioning Research, 2002; 16(1): 142-148.

45. Inbar O., Bar-Or O., Skinner JS. The wingate anaerobic test. United State of America, Champaign IL, Human Kinetics, 1996.

46. Inbar O., Chia M. Development of maximal anaerobic performance an old issue revisited (chapter 3), (Ed. Hebestreit H., Bar-Or O.), The young athlete, Singapore, Blackwell Publishing, 2008.

47. Jensen K., Larsson B. Variations in physical capacity among the Danish national soccer team for women during a period of supplemental training. Journal of Sports Sciences, 1992; 10: 144-145.

48. Kearney JT., Rundell KW., Wilber RL. Measurement of work and power in sport (chapter IV). (Ed. Garrett, W.E., Kirkendall, T.D.), Exercise and sport science, Philadelphia, Lippincott Williams \& Wilkins, 2000.

49. Kobayashi Y., Narazaki K., Akagi R., Nakagaki K., Kawamori N., Ohta K. Calculation of force and power during bench throws using a smith machine: The importance of considering the effect of counterweights. International Journal of Sports Medicine, 2013; 34(9): 820824.

50. Krustrup P., Mohr M., Amstrup T., Rysgaar T., Johansen J., Steensberg A., Pedersen P., Bangsbo J. The Yo-Yo intermittent recovery test: Physiological response, reliability, and validity. Medicine Sciences and Sports Exercise, 2003; 35(4): 697-705.

51. Krustrup P., Mohr M., Ellingsgaar H., Bangsbo J. Physical demands during an elite female soccer game: Importance of 
training status. Medicine Sciences and Sports Exercise, 2005; 37(7): 1242-1248.

52. Krustrup P., Zebis M., Jensen JM., Mohr M. Game-induced fatigue patterns in elite female soccer. Journal of Strength and Conditioning Research, 2010; 24(2): 437-441.

53. Little T., Williams GA. Specifity of acceleration, maximal speed and agility in professional soccer players. Journal of Strength and Conditioning Research, 2005; 19(1): 76-78.

54. Loturco I., Artioli GG., Kobal R., Gil S., Franchini E. Predicting punching acceleration from selected strength and power variables in elite karate athletes: A multiple regression analysis. Journal of Strength and Conditioning Research, 2014; 28(7): 1826-1832.

55. Loturco I., D'Angelo RA., Fernandes V., Gil S., Kobal R., CalAbad CC., Kitamura K., Nakamura FY. Relationship between sprint ability and loaded/unloaded jump tests in elite sprinters. Journal of Strength and Conditioning Research, 2015; 29(3), 758-764.

56. Mackenzie B. 101 Performance Evaluation Tests, London: Electric Word Plc, 2015.

57. Man CT. Validation of a new-developed soccer specific field test in female soccer players (Unpublished Thesis), Physical Education and Recreaction Management, Hong Kong Baptist University, 2009.

58. Martinez-Luganas V., Coyle EF. Validity of the 1beep test" in estimating $\mathrm{VO}_{2 \max }$ among female college soccer players. Medicine Sciences and Sports Exercise, 2006; 38(5): 509.

59. Martinez-Lagunas V., Gotz JK., Niessen M., Hermsdorf M., Hartmann U. Aerobic characteristics of german female soccer players of two different competitive levels. Final program of the $60^{\text {th }}$ Annual Meeting of the American College of Sports Medicine, Indianapolis. 2013; 139.

60. Martinez-Lagunas V., Hartmann U. Validity of the Yo-Yo intermittent recovery test level 1 for direct measurement or indirect estimation of maximal oxygen uptake in female soccer players. International Journal of Sports Physiology Performance, 2014; 9(5): 825-831.

61. Martinez-Luganas V., Niessen M., Hartmann U. A Women's football: Player characteristics and demands of the game. Journal of Sport and Health Sceince, 2014; 3(4): 258-272.

62. McCurdy WK., Walker LJ., Langford AG., Kutz RM., Guerrero MJ., McMillan J. The relationship between kinematic determinants of jump and sprint performance in division I women soccer players. Journal of Strength and Conditioning Research, 2010; 24(12): 3200-3208.

63. Milanovic Z., Sporis G., Trajkovic N. Differences in body composite and physical match performance in female soccer players according to team position. $6^{\text {th }}$ INSHS International Christmas Sport Scientific Conference, Hungary, 2011; 6772.

64. Miles A., MacLaren D., Reilly T., Yamanaka K. An analysis of physiological strain in four a side women's soccer. Science and Football II (Ed. Reilly, T., Clarys, J., Stibbe, A.), London: 1993; 140-145.

65. Mohr M., Krustrup P., Andersson H., Kırkendal D., Bangsbo J. Match activities of elite women soccer players at different performance levels. Journal of Strength and Conditioning Research, 2008; 22(2): 341-349.

66. Mujika I., Santisteban J., Impellizzeri FM., Castagna C. Fitness determinants of success in men's and women's football. Journal of Sports Sciences, 2009; 27(2): 107-114.

67. Newton RU., Kraemer JW. Developing explosive muscular power: Implications for a mixed methods training strategy. Strength and Conditioning, 1994; 16(5), 20-31.
68. Nikolaidis PT. Physical fitness in female soccer players by player position: A focus on anaerobic power. Human Movement, 2014; 15(2): 74-79.

69. Nikolaidis PT. Weight status and physical fitness in female soccer players: is there an optimal BMI. Sport Science of Health, 2014; 10(1): 41-48.

70. Nobelsick-Gullett LJ., Housh TJ., Johnson GO., Bauge SM. A comparison between methods of measuring anaerobic work capacity. Ergonomics, 1988; 31(10): 1413-1419.

71. Ostojic MS. Physical and physiological characteristics of elite Serbian soccer players. Physical Education and Sport, 2010; 1(7): 23-29.

72. Özkan A., Köklü Y., Ersöz G. Wingate anaerobic power test. International Journal of Human Sciences, 2010; 7(1): 207-224.

73. Parsons LS., Jones MT. Development of speed, agility and quickness for tennis athletes. Strength and Conditioning Journal, 1998; 20(3): 14-19.

74. Perez-Gomez J., Rodrigez GV., Ara I., Olmedillas H., Chavarren J, Gonzalaez-Henriquez JJ., Dorado C., Calbet JAL. Role of muscle mass on sprint performance: Gender differences. European Journal of Applied Physiology, 2008; 102(6): 685-694.

75. Polman R., Walsh D., Bloomfield J., Nesti M. Effective conditioning of female soccer players. Journal of Sport Sciences, 2004; 22(2): 191-203.

76. Plowman AS., Smith LD. Exercise physiology for health, fitness and performance. Philadelphia, Lippincott Williams / Wilkins, 2008.

77. Rampinini E., Bishop D., Marcora S., Bravo FD., Sassi R., Impellizzeri F. Validity of simple field tests as indicators of match-related physical performance in top-level professional soccer players. International Journal of Sports Medicine, 2007; 28(3): 228-235.

78. Reilly T., Thomas V. A motion analysis of work-rate in different positional roles in professional football matchplay. Journal of Human Movement Studies, 1976; 2: 87-97.

79. Reilly T. Energetics of high intensity exercise (soccer) with particular reference to fatigue. Journal of Sport Sciences, 1997; 15: 257-263.

80. Reilly T., Bangsbo J., Franks A. Anthropometric and physiological predispositions for elite soccer. Journal of Sport Sciences, 2000; 18(9): 669-683.

81. Rhodes EC., Mosher RE. Aerobic and anaerobic characteristics of elite female university players. Journal of Sport Sciences, 1992; 10: 143-144.

82. Rienzi E., Drust B., Reilly T., Carter JEL., Martin A. Investigation of anthropometric and work-rate profiles of elite South American international soccer players. Journal of Sports Medicine and Physical Fitness, 2000; 40(2): 162-169.

83. Ronnestad B., Kvamme N., Sunde A., Raastad T. Short-term effects of strength and plyometric training on sprint and jump performance in professional soccer players. Journal of Strength and Conditioning Research, 2008; 22(3): 773-780.

84. Sale DG. Neural adaptation to strength training. (Ed. Komi, P.V.). Strength and power in sport. Oxford: Blackwell Science, 2003; 281-314.

85. Sanchez-Medina L., Perez CE., Gonzales-Badillo JJ. Importance of the propulsive phase in strength assessment. International Journal of Sports Medicine, 2010; 31(2): 123129.

86. Sanchez-Medina L., Gonzales-Badillo JJ., Perez CE., GarciaPallares J. Velocity and power-load relationship of the bench pull vs. bench press xxercises. International Journal of Sports Medicine, 2014; 35(3): 209-216.

87. Sevim, Y. Antrenman Bilgisi. Nobel Yayınları, Ankara: 2007; 380-381. 
88. Sezgin E., Cihan H., Can İ. Comparison of the aerobic power performances and recovery times according to playing positions of elite women football players. Spormetre, 2011; 9(4): 125-130.

89. Sheppard JM., Young WB. Agility literature review: Classifications, training and testing. Journal of Sports Sciences, 2006; 24(9): 919-932.

90. Sjökvist J., Laurent MC., Richardson M., Curtner-Smith M., Hans-Christer H., Bishop PA. Recovery from high intensity training sessions in female soccer players. Journal of Strength and Conditioning Research, 2011; 25(6): 1726-1735.

91. Smith R., Ford RK., Myer DG., Holleran A., Treadway E., Hewett ET. Biomechanical and performance differences between female soccer athletes in national collegiate athletic association divisions I and III. Journal of Athletic Training, 2007; 42(4): 470-476.

92. Sproule J., Kunalan C., McNeill M., Wright H. Validity of 20-MST for predicting $\mathrm{VO}_{2 \max }$ of adult Singaporean athletes. British Journal of Sports Medicine, 1993; 27(3): 202-204.

93. Stolen T., Chamari K., Castagna C., Wisloff U. Physiology of soccer. Sport Medicine, 2005; 35(6): 501-536.

94. Stone MH., Sanborn K., O'Bryant HS., Hartman M., Stone ME, Proulx C., Ward B., Hruby J. Maximum strengthpower-performance relationships in college throwers. Journal of Strength and Conditioning Research, 2003; 17(4): 739-745.

95. Tamer K., Gunay M., Tiryaki G., Cicioolu I., Erol E. Physiological characteristics of Turkish female soccer players. Science and Football III (Ed. Reilly, T., Bangsbo, J., Hughes, M.), London: 1997; 37-39.

96. Thomas C., Plowman SS., Looney MA. Reliability and validity of the anaerobic speed test and the field anaerobic shuttle test for measuring anaerobic work capacity in soccer players. Measurement in Physical Education and Exercise Science, 2002; 6(3): 187-205.

97. Todd MK., Scott D., Chisnall PJ. Fitness characteristics of England female soccer players: An analysis by position and playing standart. Science and Football IV (Ed. Spinks, W., Reilly, T., Murphy, A.) London Routledge: 2002; 374-381.

98. Tumilty D., Darby S. Physiological characteristics of Australian female soccer players. Journal of Sport Sciences, 1992; 10: 145.

99. Twist PW., Benickly D. Conditioning lateral movements for multi-sport athletes: Practical strength and quickness drills. Strength and Conditioning Journal, 1996; 18(5): 10-19.

100. Vescodi JD., McGuigan MR. Relationships between sprinting, agility, and jump ability in female athletes. Journal of Sports Sciences, 2008; 26(1): 97-107.

101. Wisloff U., Castagna C., Helgerud J., Jones R., Hoff J. Strong correlation of maximal squat strength with sprint performance and vertical jump height in elite soccer players. British Journal of Sports Medicine, 2004; 38(3): 285-288.

102. Young W., Mclean B., Ardagna J. Relationship between strength qualities and sprinting performance. Journal of Sport Medicine and Physical Fittness, 1995; 35(1): 13-19.

103. Young WB., James R., Montgomery I. Is muscle power related to speed with changes of direction. Journal of Sport Medicine, 2002; 42(3): 282-288.

104. Zatsiorsky VM. Kinematics of human motion. United States: Human Kinetics, 1998; 148-192. 